\title{
Berne fédérale: arrêts sur image
}

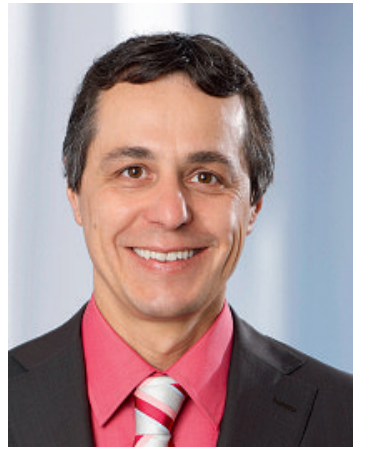

Le Parlement aurait déjà dû adopter le projet de loi sur le Managed care lors de la session d'hiver 2010. Mais les politiciens prennent leur temps: après tout, il s'agit là d'une importante réforme du système de santé! Le 3 mars 2011, le Conseil national a - contre l'avis du Conseil des Etats - insisté sur l'indépendance des réseaux de soins intégrés face aux caisses-maladie et sur l'obligation de ces dernières de proposer des modèles de soins intégrés dans l'ensemble de la Suisse. Une troisième divergence concerne la quote-part de participation aux coûts à l'intérieur et à l'extérieur des réseaux: le Conseil national préconise des taux de 10 et $20 \%$, le Conseil des Etats de 5 et $15 \%$ et le Conseil fédéral de 7,5 et $15 \%$. Ce sont là les principales divergences. En revanche, d'autres principes-clés ont été

\section{Managed care: le Conseil national soutient l'indépendance des réseaux de soins intégrés face aux caisses-maladie.}

adoptés: l'amélioration de la compensation des risques, le principe d'incitatifs financiers (primes différenciées et participation aux coûts), la mention explicite de la qualité, la coresponsabilité budgétaire et la liberté de contracter pour les assureurs et les réseaux de médecins.

Le Parlement a également adopté le premier volet de la $6^{\text {e }}$ révision de $1^{\prime} A I$. Les $4^{\mathrm{e}}, 5^{\mathrm{e}}$ et $6^{\mathrm{e}}$ révisions ainsi que l'augmentation de la TVA visent à remettre cette importante assurance sociale à flot et à la rendre viable pour les générations à venir. L'Association du Coup du Lapin s'insurge toutefois contre les coupes dans les prestations et a décidé de lancer un référendum; elle se cherche à présent des alliances.

Par ailleurs, l'arrêt capital qu'a pris le Tribunal fédéral (TF) le 23 novembre 2010 (9C_334/2010) a suscité de vives discussions informelles. Outre la question en tant que telle (remboursement du médicament Myozyme $^{\circledR}$ contre la maladie de Pompe), le TF a pris position sur les questions fondamentales du rapport coût-efficacité des mesures médicales, du rationnement, et des seuils de remboursement. Et ce, en se référant à des critères d'évaluation du rapport coût-efficacité qui ne sont pas encore définis sur le plan politique. C'est pourquoi la conseillère nationale Ruth Humbel a déposé une interpellation [1], et moi-même un postulat [2], de manière à poursuivre la discussion sur les plans politique et social.
Par ailleurs, le Conseil national a transmis sans discuter un postulat de sa Commission de la santé portant sur la prescription de médicaments par les hôpitaux (voir numéro d'objet 10.3669 sur www.parlement.ch, Curia Vista-Banque de données des objets parlementaires). Le Conseil fédéral est ainsi chargé de vérifier si et à quelles conditions il serait possible d'interdire aux hôpitaux de prescrire des produits de marque aux patients à leur sortie, pour les contraindre à ne

\section{L'arrêt du Tribunal fédéral sur le rapport coût-efficacité des mesures médicales suscite de vives discussions.}

prescrire que les principes actifs, leur dosage, leur forme galénique ainsi que la taille de l'emballage. Le Conseil national a également confirmé tacitement l'introduction du nouveau système de rémunération SwissDRG, prévue le $1^{\text {er }}$ janvier 2012, et il a, sur la base d'une motion déposée par sa Commission de la sécurité sociale et de la santé publique, chargé le Conseil fédéral de créer les conditions cadres nécessaires à garantir la formation pré- et postgraduée des médecins et de l'ensemble du personnel soignant, ainsi que la qualité des soins [3].

Enfin ces dernières semaines, trois partis, le PDC, le PLR et l'UDC, ont exprimé leur inquiétude au sujet de la mise en œuvre du nouveau financement hospitalier au

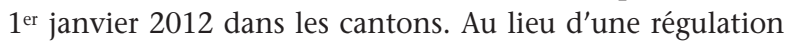
hospitalière basée sur la transparence de la qualité et des coûts, certains cantons prennent en effet des mesures visant à garantir le maintien des structures actuelles, ignorant ainsi la volonté du législateur - tel est notre sentiment. Une interpellation a été déposée à ce sujet [4]. Lors de la prochaine session spéciale, du 11 au 14 avril 2011, ce sera au tour de la Loi sur la prévention d'être soumise à délibération: d'intéressantes discussions en perspective. A suivre!

Dr Ignazio Cassis

Vice-président de la FMH et Conseiller national

\section{Références}

1 11.3154: Un arrêt du Tribunal fédéral marquant le coup d'envoi du rationnement médical?

2 11.3218: Combien doit payer la société pour une année de vie supplémentaire? (titre non définitif).

3 10.3882: Assurer la qualité des soins lors de l'introduction des DRG.

4 11.3032: Financement hospitalier: tout change pour que rien ne change? 